\title{
Two-week global trends on 2019-nCoV fatality and virulence rates: a cross-sectional study
}

Jorge Arroz ( $\square$ jarroz2010@gmail.com )

Ordem dos Médicos de Moçambique, Maputo, Mozambique

Research article

Keywords: 2019-nCoV, Fatality, Virulence, Cross-sectional analysis

Posted Date: February 21st, 2020

DOI: https://doi.org/10.21203/rs.2.23981/v1

License: (9) This work is licensed under a Creative Commons Attribution 4.0 International License.

Read Full License 


\section{Abstract}

\section{Background}

The recent Public Health Emergency of International Concern, caused by a novel coronavirus (2019-nCoV) is fast spreading, and contribution for the increase of knowledge about this outbreak is desired. The aim of this study is to analyse the global trend of 2019-nCoV fatality and virulence rates from 24 January to 06 February 2020.

\section{Methods}

A cross-sectional study was carried out. Data from 2019-nCoV, Severe Acute Respiratory Syndrome coronavirus (SARS-CoV) and Middle East Respiratory Syndrome coronavirus (MERS CoV) were obtained from World Health Organization. Only confirmed cases and deaths directly attributed to these viruses were considered. For 2019-nCoV, severe illness was also considered. Two endpoints of interest were analysed: trends in fatality rate (death among confirmed cases $x 100$ ) and virulence rate (severe illness among confirmed cases $\times 100$ ).

\section{Results}

The 2019-nCoV fatality and virulence rate decreased 1.0 and 7.3 percent points during the analysed timeframe, respectively. The SARS-CoV and MERS-CoV fatality rate are five and 17 times higher than the current 2019-nCoV fatality rate. The current cumulative 2019-nCoV confirmed cases exceeded 3.5 and 11.3 times the SARS-CoV and MERS-CoV confirmed cases, respectivelly.

\section{Conclusions}

A reduction in fatality and virulence rate associated with the novel coronavirus was observed in the analyzed time-frame. The novel coronavirus is spreading at higher rates than SARS-CoV and MERS-CoV, although with comparative lower fatality rates. Continuous surveillance using additional indicators such as virulence rate (in addition to the fatality rate) may contribute to broaden and deepen the knowledge about the novel coronavirus.

\section{Background}

The outbreak of the novel coronavirus (2019-nCoV) in China in the last December raised global concern leading World Health Organization (WHO) declaring the outbreak as a Public Health Emergency of International Concern on 30 January 2020 [1]. By 06 of February (two month form the first case) the number of confirmed cases was at 28,276 and the death toll was at 565 (564 deaths in China and 1 death outside of China - from Philippines, reported on 02 February 2020), with 3,859 cumulative severe illness, and affecting 24 countries outside of China [2]. Although 2019-nCoV is related to coronavirus responsible for the Severe Acute Respiratory Syndrome (SARS-CoV) and the coronavirus responsible for Middle East Respiratory Syndrome (MERS-CoV), the current evidence suggests that they are less 
genetically similar [3]. The knowledge about the 2019-nCoV is evolving, and transmission from asymptomatic patient have been reported [4]. Zhao et al. [5] reported on basic reproduction number, Ro, with an estimate of 3.30 to 5.47. Li et al. [6] reported an estimated Ro of 2.2, although this estimate was limited to the period up to January 4, being therefore underestimated. The purpose of this study is to contribute to increase the knowledge about this novel coronavirus, analysing the global trend of 2019$\mathrm{nCoV}$ fatality and virulence rates from 24 January to 06 February 2020. Compared incidence (confirmed cases) and fatality rate from 2019-nCoV with SARS-CoV and MERS-CoV was also analysed for this period.

\section{Methods}

\section{Study design and time-frame}

A cross-sectional study was carried out. The time-frame considered for 2019-nCoV data collection was 24 January to 06 February 2020. The starting time-frame was considered because the WHO reported data were consistent from this date, although the first 2019-nCoV situation report was released on 21 January 2020 , with data as reported by 20 January 2020 . The time-frame considered for SARS-CoV data collection was from 1 November 2002 to 31 July 2003, based on data as of 31 December 2003 [7]. For MERS-CoV the time-frame considered was from September 2012 to end of November 2019 [8].

\section{Source of data and eligibility}

Data from 2019-nCoV, SARS-CoV and MERS CoV were obtained from WHO web site [7-9]. Only confirmed cases and deaths directly attributed to these viruses were considered. For 2019-nCoV, severe illness was also considered, according to one of the following WHO criteria: (1) dyspnea; (2) respiratory rate more than 30 cycles per minute; (3) hypoxemia; (4) chest X-ray with multi-lobar infiltrates or pulmonary infiltration progressed more than $50 \%$ within 24 - 48 hours [10].

\section{Endpoints of interest}

Two endpoints of interest were analysed: trends in fatality rate (death among confirmed cases $x 100$ ) and virulence rate (severe illness among confirmed cases $x 100$ ). Virulence is herein used to refer the ability of the virus to 'harm' the host, leading to severe cases which might result in death.

\section{Data processing and analysis}

All data were introduced and analysed using Microsoft Office Excel 2007. Fatality rate was calculated for 2019-nCoV, SARS-CoV, and MERS-CoV. Virulence rate was only calculated for 2019-nCoV (no data about SARS-CoV and MERS-CoV severe illness was found on WHO web site). Linear type charts related with the endpoints of interest were generated. Mean 2019-nCoV daily confirmed cases, deaths, and severe illness for the defined time-frame was also calculated. In order to compare the incidence (confirmed cases) and fatality rate from 2019-nCoV with SARS-CoV and MERS-CoV, the following formula was applied: 
- Confirmed cases of 2019-nCoV divided by confirmed cases of SARS-CoV and MERS-CoV;

- Fatality rate of SARS-CoV and MERS-CoV divided by fatality rate of 2019-nCoV - an illustrative chart was generated.

\section{Results}

During the selected time-frame, an average of: 1,978 confirmed cases, 39 deaths and 269 severe illness by 2019-nCoV were reported by WHO. An ascendant daily trend of confirmed cases and deaths was observed, although the severe illness was variable, with daily report ranging from 82 to 640 (Figure 1).

The 2019-nCoV fatality and virulence rate decreased 1.0 and 7.3 percent points during the analysed timeframe, respectively (Figure 2). Current fatality rate is $2.0 \%$ and the virulence is $13.6 \%$ (Figure 2). The SARS-CoV and MERS-CoV fatality rate are five and 17 times higher than the current 2019-nCoV fatality rate, respectivelly (Figure 3). The current cumulative 2019-nCoV confirmed cases exceeded 3.5 $(28,276 / 8,096)$ and $11.3(28,276 / 2,494)$ times the SARS-CoV and MERS-CoV confirmed cases, respectivelly.

\section{Discussion}

This study shows that there is a global reduction in the fatality and virulence rate trends of the 2019nCoV from 24 January to 06 February 2020, although the number of daily cases and deaths are increasing. In only two months, the 2019-nCoV confirmed cases exceeded the number of confirmed SARS-CoV (3.5 times) and MERS-CoV (11.3 times), although the fatality rate is currently five times higher for SARS-CoV and 17 times higher for MERS-CoV.

The initial relatively high fatality and virulence rate might be a reflex of a bias induced by the early stage of the outbreak, with more severe cases, and less implementation of health promotion and preventive measures. However, the subsequent observed reduction in fatality and virulence rate trend might be explained by: 1) increased screening capability (active surveillance for new cases and close monitoring of their contacts were implemented) [11] with more suspected and tested cases, thus increasing the number of 2019-nCoV confirmed cases which dilutes the increased number of daily deaths associated, 2) expansion of health care services provided by Chinese health professionals (increase in the number of quarantine sites, availability of more beds to cope with the surging confirmed or suspected cases, availability of rapid point-of-care diagnostic tests, availability of case management standard guidelines, among others), 3) highest priority given by Chinese health authorities (examples: quarantine measure adoption, build a hospital in a short time, sharing information with other countries, among others), and 4) as more is known about the virus, better are the case management capabilities. The fatality and virulence rate trend in the future is more likely to reduce as the spectrum of mild or asymptomatic infection becomes available. However, if the disease spread to low-middle income countries, with fragile health systems such as the majority of countries in Africa, the fatality and virulence rate might well increase. The future trend is uncertain, and other parameters are needed to better predict the trend. 
Three major aspects might explain the spreading rate and the exceeding 2019-nCoV confirmed cases than SARS-CoV and MERS-CoV: 1) 2019-nCoV Ro (based on the estimates of Zhao et al.) [5] is slightly higher than those of SARS-CoV (approximately 3) [12] and MERS-CoV (2.7 - 3.9) [13]; 2) potential SuperSpreading Events (SSEs - certain individuals or situations generates extraordinarily large numbers of secondary cases) [12], already observed in SARS-CoV [14, 15] and MERS-CoV [16]; 3) the potential of transmission before the symptoms onset (from asymptomatic contacts), i.e., during incubation period [4]; and 4) high mutation rate which provides the possibility for the virus to adapt and to become more efficiently transmitted from person to person [11]. In fact, the number of 2019-nCoV cases could be higher if the Chinese authorities had not been adopted restrictive preventive measures on 23 of January, such as: the suspension of public transportation, with closure of airports, railway stations, and highways in the city, among others [17].

The early detection and report on 31 December 2019 to WHO of a pneumonia of unknown aetiology [10, 18], with subsequent close of the seafood market (highly suspected primary focus) in Whuan on 01 January 2020, and rapidly isolation of the causative agent (on 07 January 2020) [10], are positive aspects that might well explain partially the relative low fatality rate of 2019-nCoV when compared with SARS-CoV and MERS-CoV. Another possible explanation is the fact that virulence is less than $20 \%$, which means that more than $80 \%$ of 2019 -nCoV cases are mild to moderate. Many other factors (discussed above) can contribute to this relative low fatality rate, and as the knowledge about the virus is increasing, multifaceted factors can be disclosure.

\section{Limitations}

The analysis of only two weeks is a limitation of the study. Another limitation is the absence of data of severe SARS-CoV and MERS-CoV to compare the virulence rate with the novel coronavirus. Despite these limitations, this study (alongside with others published on novel coronavirus) provides insights for a better comprehension of the Wuhan pneumonia outbreak.

\section{Conclusion}

A reduction in fatality and virulence rate associated with the novel coronavirus was observed in the analyzed time-frame, although the number of confirmed cases and deaths are daily increasing. The novel coronavirus is spreading at higher rates than SARS-CoV and MERS-CoV, although with lower comparative fatality rates. Continuous surveillance using additional indicators such as virulence rate (in addition to the fatality rate) may broaden and deepen the knowledge about the novel coronavirus. Understanding the existence of super-spreading events might give additional inputs for the control of the outbreak.

\section{Abbreviations}

2019-nCoV - Novel coronavirus; MERS-CoV - Middle East Respiratory Syndrome coronavirus; Ro - Basic Reproduction Number; SARS-CoV - Severe Acute Respiratory Syndrome coronavirus; SSE - Super- 
Spreading Events; WHO - World Health Organization.

\section{Declarations}

\section{Ethics approval and consent to participate}

Not applicable.

\section{Consent for publication}

Not applicable.

\section{Availability of data and materials}

The datasets generated and/or analysed during the current study are available in the World Health Organization repository, [https://www.who.int/emergencies/diseases/novel-coronavirus-2019/situationreports/].

\section{Competing interests}

The author declare that they have no competing interests

\section{Funding}

Not applicable.

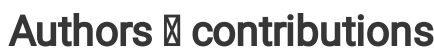

JAHA conceived the study, collected the data, performed data analysis, and wrote the manuscript.

\section{References}

1. WHO. Statement on the second meeting of the International Health Regulations (2005) Emergency Committee regarding the outbreak of novel coronavirus (2019-nCoV). Geneva, Switzerland 2020. Available from: https://www.who.int/news-room/detail/30-01-2020-statement-on-the-secondmeeting-of-the-international-health-regulations-(2005)-emergency-committee-regarding-the-outbreakof-novel-coronavirus-(2019-ncov). Access on 06 February 2020.

2. WHO. Novel Coronavirus (2019-nCoV) Situation Report - 17. Data as reported by 6 February 2020. Available from: https://www.who.int/docs/default-source/coronaviruse/situation-reports/20200206sitrep-17-ncov.pdf?sfvrsn=17f0dca_2. Access on 06 February 2020.

3. Lu R, Zhao X, Li J, Niu P, Yang B, Wu H, et al. Genomic characterisation and epidemiology of 2019 novel coronavirus: implications for virus origins and receptor Binding. The Lancet 2020. Available from: https://doi.org/10.1016/S0140-6736(20)30251-8. Access on 06 February 2020. 
4. Rothe C, Schunk M, Sothmann P, Bretzel G, Froeschl G, Wallrauch C, et al. Transmission of 2019nCoV Infection from an Asymptomatic Contact in Germany. The New England Journal of Medicine 2020. DOI: 10.1056/NEJMc2001468.

5. Zhao S, Ran J, Musa S, Yang G, Lou Y, Gao D, et al. Preliminary estimation of the basic reproduction number of novel coronavirus (2019-nCoV) in China, from 2019 to 2020: A data-driven analysis in the early phase of the outbreak. International Journal of Infectious Diseases 2020. doi: 10.1016/j.ijid.2020.01.050.

6. Li Q, Guan X, Wu P, Wang X, Zhou L, Tong Y, et al. Early Transmission Dynamics in Wuhan, China, of Novel Coronavirus-Infected Pneumonia. The New England Journal of Medicine 2020. DOI: 10.1056/NEJMoa2001316.

7. WHO. Summary of probable SARS cases with onset of illness from 1 November 2002 to 31 July 2003. Available from: https://www.who.int/csr/sars/country/table2004_04_21/en/. Access on 06 February 2020.

8. WHO. Middle East respiratory syndrome coronavirus (MERS-CoV). Available from:https://www.who.int/emergencies/mers-cov/en/. Access on 06 February 2020.

9. WHO. Novel Coronavirus (2019-nCoV) situation reports. Available from: https://www.who.int/emergencies/diseases/novel-coronavirus-2019/situation-reports/. Access on 06 February 2020.

10. WHO. Novel Coronavirus (2019-nCoV) Situation Report - 1. Data as reported by 20 January 2020. Available from: https://www.who.int/docs/default-source/coronaviruse/situation-reports/20200121sitrep-1-2019-ncov.pdf?sfvrsn=20a99c10_4. Access on 06 of February 2020.

11. Wang $C$, Horby P, Hayden F and Gao G. A novel coronavirus outbreak of global health concern. The Lancet 2020. Available from: https://doi.org/10.1016/S0140-6736(20)30185-9. Access on 06 February 2020.

12. Bauch CT, Llooyd-Smith JO, Coffe M MP, and Galvani AP. Dynamically Modeling SARS and Other Newly Emerging Respiratory Illnesses: Past, Present, and Future. Epidemiology 2005; 16(6): 791-801.

13. Lin Q, Chiu AP, Zhao S, He D: Modeling the spread of Middle East respiratory syndrome coronavirus in Saudi Arabia. Statistical methods in medical research 2018, 27(7):1968-1978.

14. Shen Z, Ning F, Zhou W, He X, Lin C, Chin DP, Zhu Z, Schuchat A. Superspreading SARS events, Beijing, 2003. Emerg Infect Dis. 2004;10:256-260.

15. Li Y, Yu IT, Xu P, Lee JH, Wong TW, Ooi PL, Sleigh AC. Predicting super spreading events during the 2003 severe acute respiratory syndrome epidemics in Hong Kong and Singapore. Am J Epidemiol. 2004;160:719-728.

16. Kucharski AJ, Althaus CL. The role of superspreading in Middle East respiratory syndrome coronavirus (MERS-CoV) transmission. Euro Surveillance 2015; 20(25):14-8.

17. Announcement from the Headquarter for novel coronavirus pneumonia prevention and control (No. 1). Beijing: China National Health Commission, 2020. Available from: http://www.gov.cn/xinwen/2020-01/23/ content_5471751.htm. Access 07 February 2020. 
18. WHO. Pneumonia of unknown cause - China. Disease outbreak news. 05 of January 2020. Available from: https://www.who.int/csr/don/05-january-2020-pneumonia-of-unkown-cause-china/en/. Access on 07 February 2020.02.07

\section{Figures}

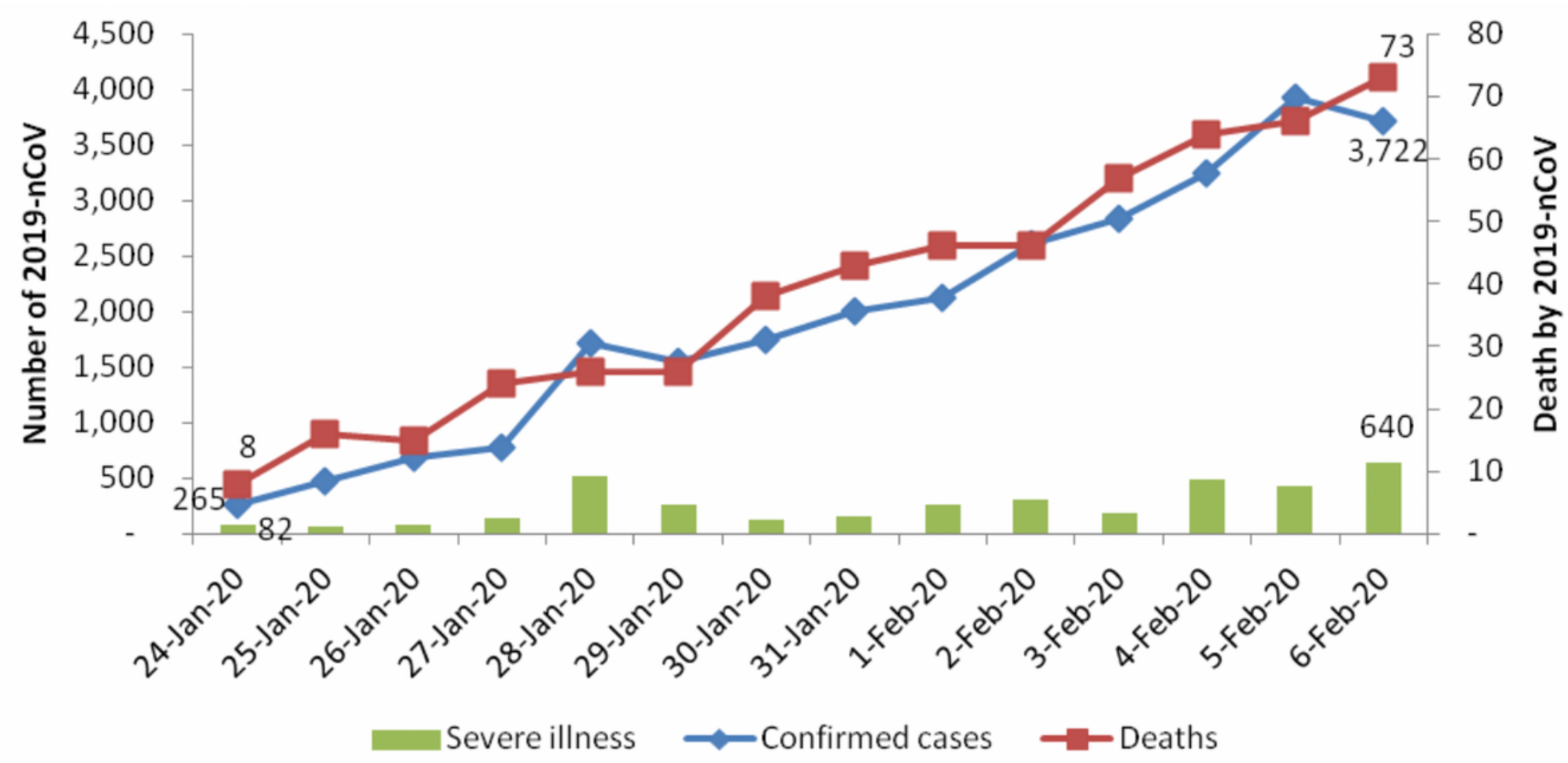

Figure 1

Global trend on daily number of confirmed cases, severe illness and deaths from 2019-nCoV

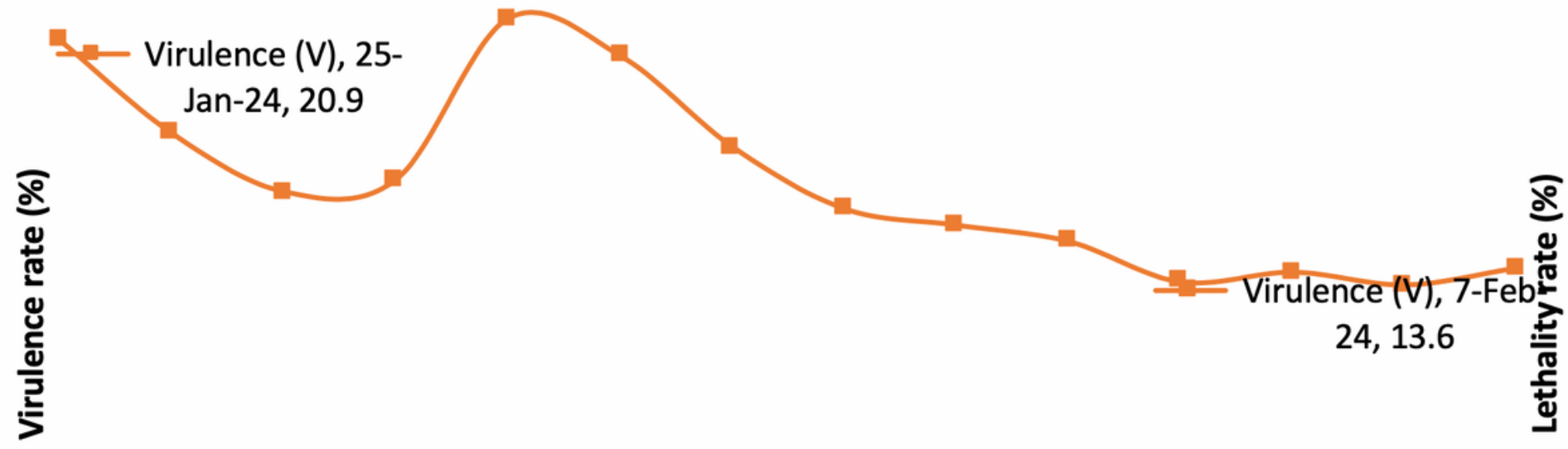

$\rightarrow$ Fatality (F), 25-Jan-

24,3.0 $\longrightarrow$ Fatality (F), 7-Feb-

$\longrightarrow$-Virulence $(\mathrm{V}) \longrightarrow$ Fatality $(\mathrm{F})$ 
Figure 2

Global trend on daily fatality and virulence rate from 2019-nCoV

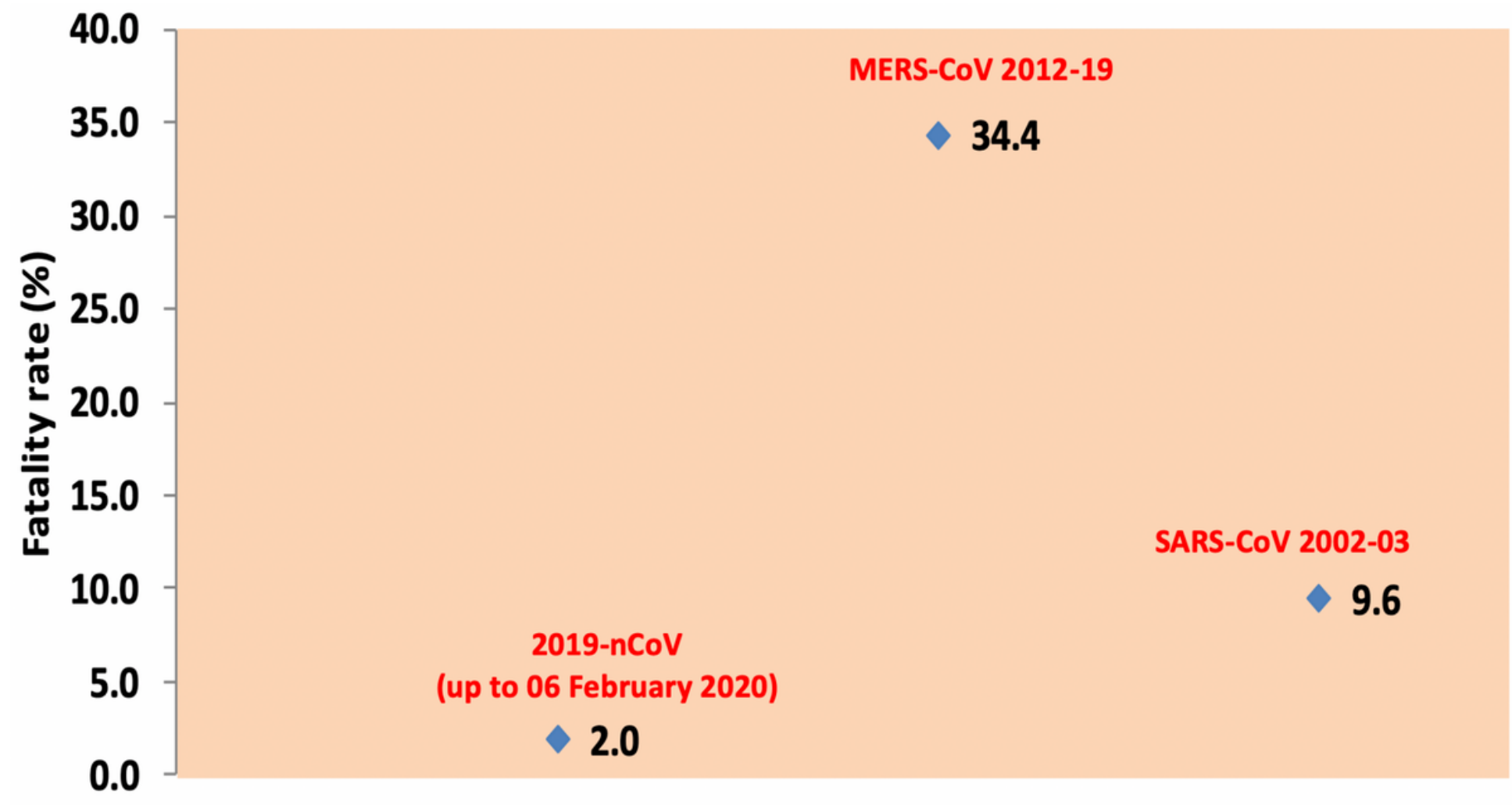

\section{Coronavirus}

Figure 3

Comparative fatality rate associated with three coronavirus: 2019-nCoV, SARS-CoV and MERS-CoV 